\title{
Research Effort and Economic Growth
}

\author{
Weshah Razzak ${ }^{1}$ (D)
}

Received: 21 April 2021 / Accepted: 24 January 2022

(c) The Author(s) 2022

\begin{abstract}
Endogenous growth models based on micro-foundations predict that total factor productivity (TFP) growth is positively associated with effective research effort. We use macroeconomic-pooled time-series-cross-sectional data for the G7 countries from 2000 to 2017 to provide a robust estimate of this positive effect of research effort on TFP growth.
\end{abstract}

Keywords TFP growth · Research efforts · Education · Human capital · Useful knowledge

JEL Classification $\mathrm{C} 2 \cdot \mathrm{C} 23 \cdot \mathrm{O} 40 \cdot \mathrm{O} 47$

\section{Introduction}

Several generations of endogenous and semi-endogenous growth models, which are based on micro-foundation at the firm level, e.g., Jones (2002), Jones and Kim (2018), and Bloom et al. (2020), model total factor productivity (TFP) growth rate as a function of effective research effort. ${ }^{1}$ This relationship is a key mechanism to drive economic growth in such models. An important assumption underlying this mechanism is that the representative firm carries out innovations in order to compete. The innovations require investments in research and development. Research effort is the product of human capital and the number of people engaged in R\&D activity. People acquire human capital by attending schools or taking up training, i.e., upskilling, hence investments in human capital. The time individuals use to attend schools or engage in training programs is the time spent out of the labor market. Therefore, when they are training to acquire human capital they are not involved

\footnotetext{
1 See Romer (1990a), Aghion and Howitt (1992), and Akcigit and Liu (2016), for examples of endogenous growth models.

Weshah Razzak

razzakw@gmail.com; w.razzak@massey.ac.nz

1 School of Economics and Finance, Massey University, Palmerston North, New Zealand
} 
in the production of output. The firms are heterogeneous. Each firm is a monopolistic competitor producing a particular product. To aggregate over firms in these models, we assume symmetry, whereby the firms choose the same starting values for their control variables; i.e., any one firm is representative of the rest. ${ }^{2}$

Bloom et al. (2020), among others, explain the observed recent decline of TFP growth in developed countries despite the increase in the number of people engaged in research over time. They use micro data to argue that although the number of researchers and research intensity has increased, research productivity has declined; hence, TFP growth declined. Their interpretation of this negative association is that research ideas have become hard to find. Dawson and Seater (2013) argue that the firm's level of TFP may fall because of the increase in the marginal tax rate and regulation. Coffey et al. (2020) use a completely different methodology and data to reach a similar conclusion for the USA.

Endogenous growth models are highly parameterized. For example, Jones (2002) has at least 12 parameters. These models are typically, but not necessarily, calibrated rather than estimated. Some of the parameters used in calibrating the models are estimates found in other microeconomic studies; others are theoretically based values used along with sensitivity analysis. As far as we know, there are no estimates of the parameters underlying the relationship between TFP growth and research effort. The objective of this paper is to estimate these parameters for the G7 countries over a sample from 2000 to 2017 , i.e., pooled time-series-cross-section data, using a variety of estimators. Furthermore, we use two different measures of TFP, one is the aggregate TFP and the other is a market economy measure of TFP, which excludes the public sector and the services sectors, where output is usually hard to measure. See the data Appendix. The evidence shows that the market measure of TFP fits the model better than the aggregate TFP measure does.

In the next section, we present the model. "Estimation" presents the data, estimation, and the results. The "Conclusion" section is a conclusion.

\section{The Model}

The typical aggregate equation that links technical progress growth to research effort in the endogenous growth literature is:

\footnotetext{
2 Phelps (1966, pp. 133-134) argues that research is an increasing function of the level of technology. Nelson and Phelps (1966, p. 70) hypothesize that educated people make good innovators, and education speeds up the process of technological diffusion. Knowledge is a key concept in the theory of economic growth. In Lucas (e.g., 1988, 2009), for example, economic growth is about ideas to produce new goods and services. New ideas do not fall from the sky; however, someone has to think about them. It was human capital in Romer (e.g., 1990a, b), and useful knowledge in Kuznets (e.g., 1973), and excess ideas in Jones (2002). Measurement notwithstanding, for knowledge, e.g., R\&D, to cause economic growth, it must eventually lead to the production of commercially viable new goods and services that enter into measured GDP; otherwise, there would be no effect on growth. The US National Laboratories, which was established in the 1940 s, recognized this fact in the 1980 s.
} 


$$
\frac{\dot{A}}{A}=H,
$$

where $A$ is the technical progress, the dot on top of it is the rate of change; thus, $\frac{\dot{A}}{A}$ is the percentage growth rate, which is proportional to the level of effective research effort $H$. Effective research effort is a function of human capital and the number of researchers.

For estimation purpose, we assume a nonlinear function for $H$,

$$
H=h^{\alpha} L^{\beta} e^{u} .
$$

Hence, $H$ is the product of the level of the stock of human capital $h$ and the number of people engaged in research $L ; \alpha$ and $\beta$ are the shares. The share of human capital is $\alpha$, the share of researchers is $\beta$, and $u$ is an error term with all classical assumptions. Next, we estimate these shares.

\section{Estimation}

To estimate the model, we test the restriction $\alpha+\beta=1$. The fit of the model improves if the restriction is valid and accepted by the data. Replace $\beta$ in Eq. (2) with $1-\alpha$. Substitute (2) in (1), log-linearizing, and rearranging the terms yields the estimable equation:

$$
\Delta \ln A_{\mathrm{t}}-\ln L_{\mathrm{t}}=\alpha\left[\ln h_{\mathrm{t}}-\ln L_{\mathrm{t}}\right]+u_{\mathrm{t}},
$$

Hence, the parameter $\alpha$ is an elasticity.

We begin by plotting the data we are using for estimation. Figure 1 plots the human capital data. Visually, the data have positive but changing trends over time. Figure 2 plots the number of researchers, which varies across the G7 countries. Canada has volatile data with a positive trend, which seems to have flattened from 2011 onward. France, Germany, and Italy have positive rising trends. Japan has volatile data and no trend. The UK data have a positive trend up to 2006, flatten thereafter to 2013, and then start rising slowly again. The US data have a positive trend, albeit volatile. In terms of magnitude, however, there are far more researchers in Japan and the USA than in any other country. Figure 3 plots the two measures of TFP, an aggregate TFP and a market measure (see the data Appendix for details). The two measures of TFP are significantly different. The market measure excludes the government public institutions and other service sectors, where output is "hard to measure"; hence, it is more reliable than aggregate TFP. Figure 4 is a scatter plot of TFP growth rate per researcher, aggregate measure, and human capital per researcher, i.e., the dependent $\left(\Delta \ln A_{\mathrm{t}}-\ln L_{\mathrm{t}}\right)$ and the independent $\left[\ln h_{\mathrm{t}}-\ln L_{\mathrm{t}}\right]$ variables in Eq. (3). ${ }^{3}$ We expect the regressions to reflect these high correlations.

\footnotetext{
${ }^{3}$ We use a $95 \%$ chi-squared test for correlation.
} 


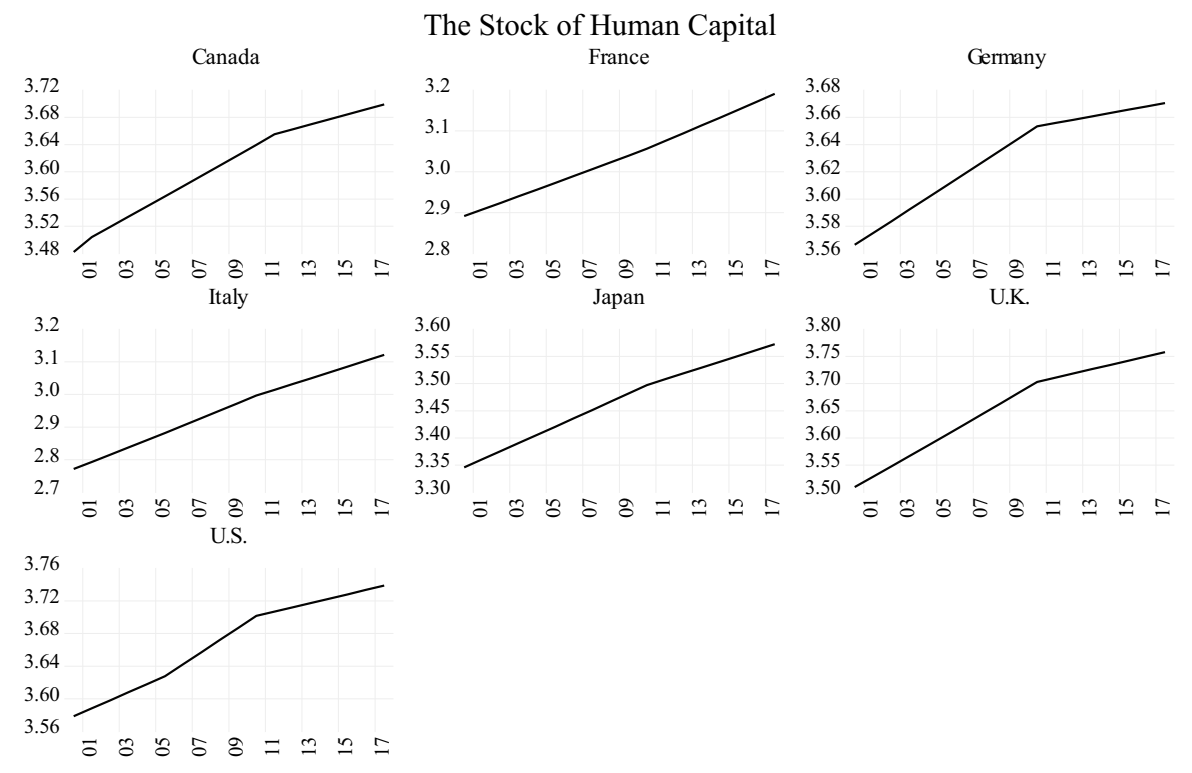

Fig. 1 The stock of human capital

The estimation of Eq. (3) is straightforward; however, there are two estimation problems, which require remedies. First, the time-series sample from 2000 to 2017 is short, hence a small sample bias. Second is the potential endogeneity problem, human capital and the number of researchers, i.e., single-equation bias problem.

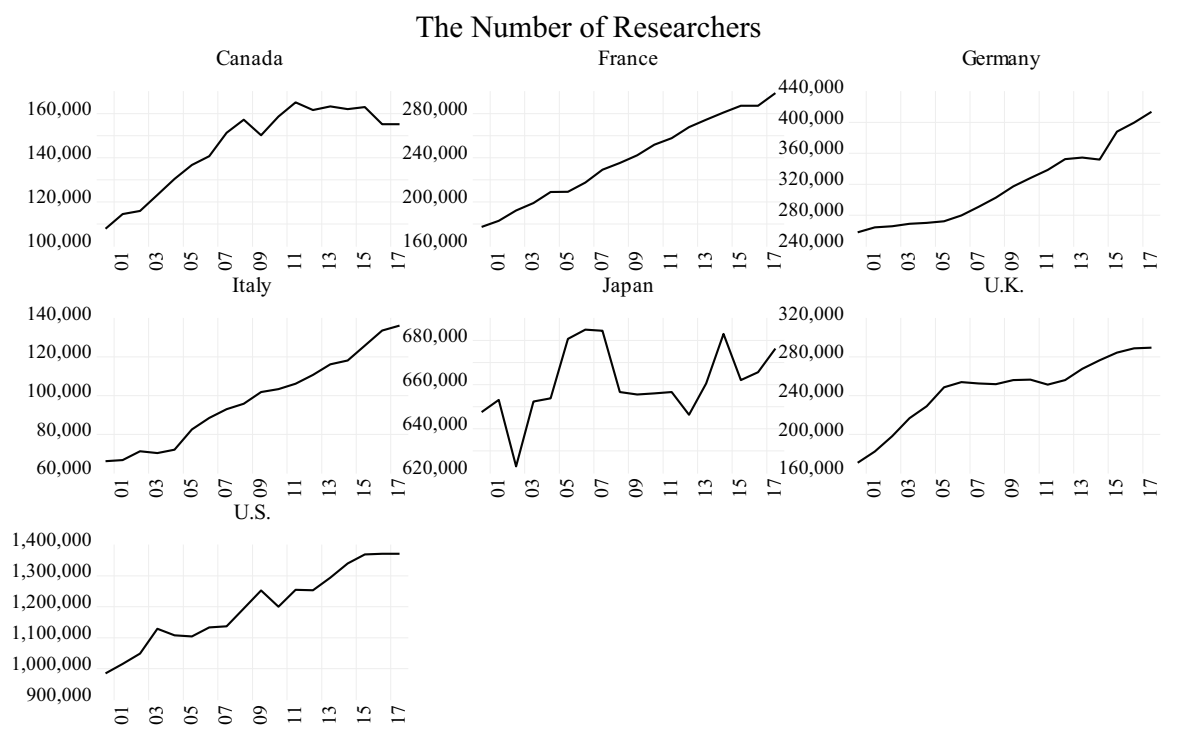

Fig. 2 The number of researchers 


\section{Aggregate and Market TFP}
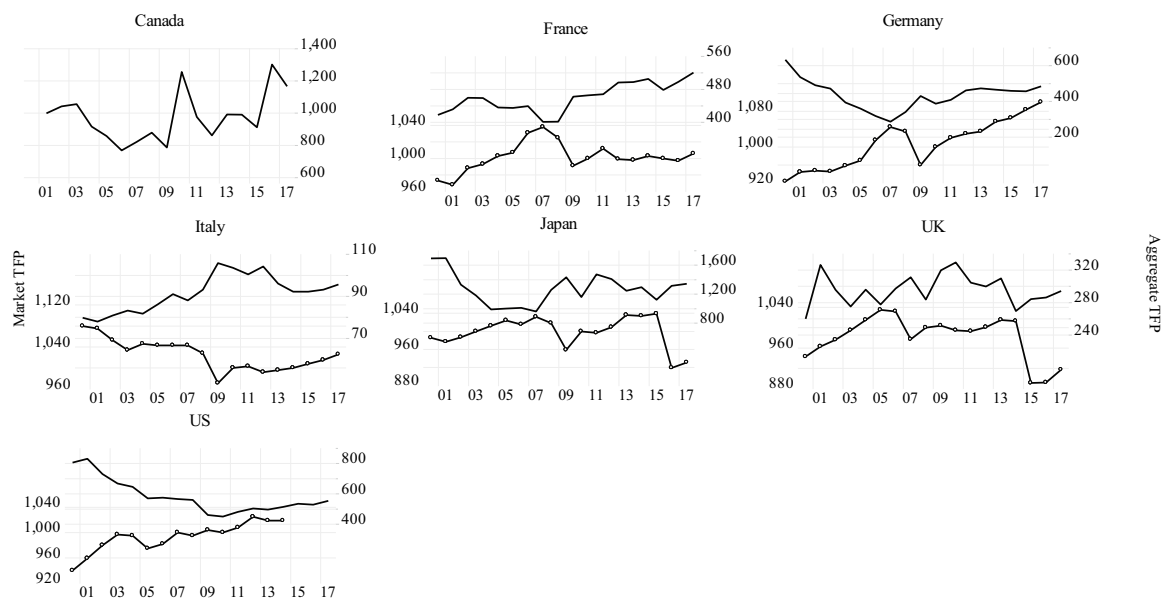

— Aggregate TFP ـ Market TFP

Fig. 3 Aggregate and market TFP

Investments in human capital and in the number of researchers are endogenous decisions.

To resolve the small sample problem, we estimate a pooled times-series-crosssectional data for the $\mathrm{G} 7$ from 2000 to 2017 . We remedy the endogeneity problem by using an instrumental variable (IV) estimator. We use the generalized method of moments (GMM). The key advantage of GMM is that it requires specification only of a certain moment rather than the full density. The drawback is that GMM may not make efficient use of all the information in the sample. For this reason, we use, in addition, the two-stage least squares (2SLS) estimator. For proof of the asymptotic efficiency, see Wooldridge (2001, pp. 96-97). For each of the IV estimators, we use two different sets of instruments. The first set includes a constant term, and lagged values of the regressor. The second set of instruments includes the population's distribution, i.e., ages 15-19 to 60-64 years. These instruments are consistent with the Life-Cycle Hypothesis, whereby investments in human capital and in the number of researchers increase with age, level up at a certain age, and then decline, as people get older. We test the instruments for relevance, i.e., identified, highly correlated with the regressor, uncorrelated with the error term, and strictly exogenous as required.

\section{Estimation Using the Aggregate TFP Measure}

To deal with both the small sample and the endogeneity problems jointly, we estimate a fixed-effect pooled time-series-cross-sector equation using 2SLS and GMM, 
Aggregate Measure of TFP Growth and Human Capital Level per Researcher

Canada

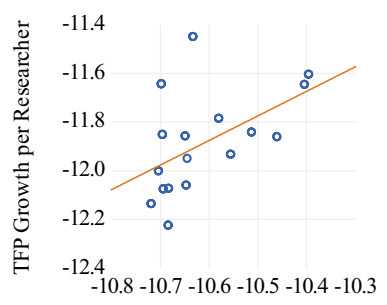

Log Human Capital per Researcher

Italy

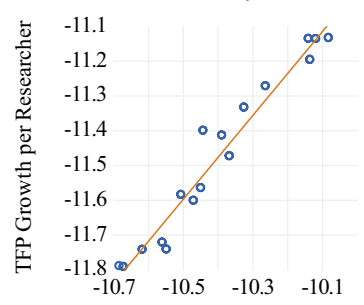

Log Human Capital per Researcher

U.S.

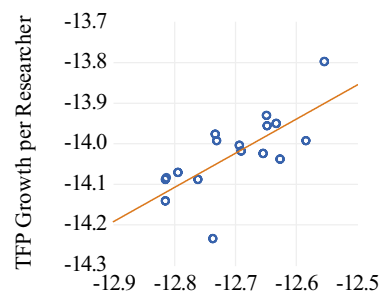

Log Human Capital per Researcher
France

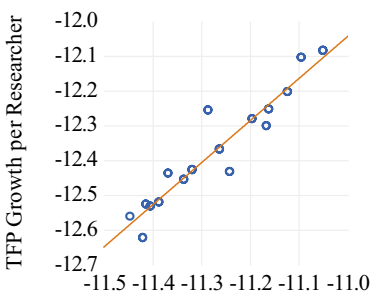

Log Human Capital per Researcher

Japan

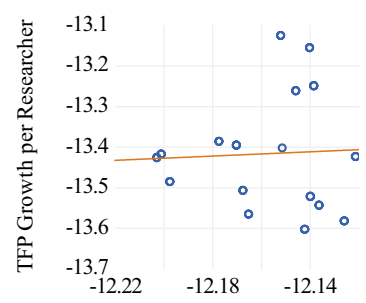

Log Human Capital per Researcher
Germany

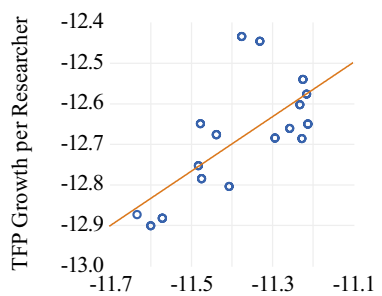

Log Human Capital per Researcher

U.K.

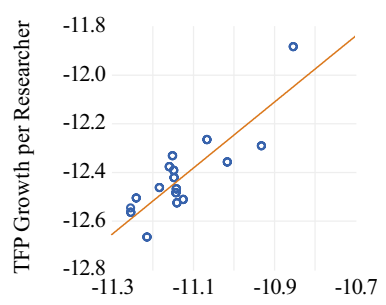

Log Human Capital per Researcher

Fig. 4 Aggregate measure of TFP growth and human capital level per researcher

but we also report estimated generalized least squares (EGLS) as a benchmark. The equation, fixed-effect model, is given by ${ }^{4}$ :

$$
\Delta \ln \left(A_{\mathrm{it}}\right)-\ln \left(L_{\mathrm{it}}\right)=\alpha\left[\left(\ln \left(h_{\mathrm{it}}\right)-\ln \left(L_{\mathrm{it}}\right)\right]+u_{\mathrm{it}},\right.
$$

where $u_{\mathrm{it}}=\eta_{\mathrm{i}}+v_{\mathrm{it}}$ and the subscript $i=1 \ldots 7, \mathrm{G} 7$ countries.

Table 1 reports the EGLS estimates. Two estimates are reported, one is in the top row of the table, where we interpret $\alpha$ as an average across all the G7 countries because it does not vary across countries, and the other is where $\alpha$ varies across

\footnotetext{
${ }^{4}$ We have estimated Eq. (3) for each country individually from 2000 to 2017 using OLS, 2SLS, and GMM. We do not report these regressions because of the small sample bias. Therefore, the individual country time-series estimates could be uninformative.
} 
Table 1 EGLS estimates of pooled time-series-cross-section data. Sample (2000-2017) $\times 7 . \Delta \ln A_{\mathrm{it}}$ $-\ln L_{\mathrm{it}}=\alpha\left(\ln h_{\mathrm{it}}-\ln L_{\mathrm{it}}\right)+u_{\mathrm{it}}, u_{\mathrm{it}}=\eta_{\mathrm{i}}+v_{\mathrm{it}}$. The dependent variable is based on an aggregate measure TFP

\begin{tabular}{llllllll}
\hline & Estimate & $P$ value & Wald & $R^{2}$ & DW & $\sigma$ & Implied $\beta$ \\
\hline $\boldsymbol{\alpha}$ & 1.15 & $(0.0000)$ & $(0.0001)$ & 0.98 & 2.11 & 0.11 & -0.15 \\
$\boldsymbol{\alpha}_{\mathbf{i}}$ & & & & & & & \\
Canada & 0.96 & $(0.0000)$ & $(0.9391)$ & & & & 0.00 \\
France & 1.21 & $(0.0000)$ & $(0.0025)$ & & & & -0.21 \\
Germany & 0.67 & $(0.0000)$ & $(0.0018)$ & & & & 0.33 \\
Italy & 1.20 & $(0.0000)$ & $(0.0000)$ & & & & -0.20 \\
Japan & 0.26 & $(0.7786)$ & NA & & & & NA \\
UK & 1.35 & $(0.0000)$ & $(0.2283)$ & & & 0.00 \\
USA & 0.84 & $(0.0000)$ & $(0.4065)$ & & & 0.00 \\
$\bar{R}^{2}$ & 0.99 & & & & & \\
DW & 2.29 & & & & & \\
$\sigma$ & 0.11 & & & & & \\
\hline
\end{tabular}

$A_{\mathrm{t}}$ is the aggregate TFP measure; $h_{\mathrm{t}}$ is the human capital; and $L_{\mathrm{t}}$ is the number of researchers

$P$ values are in parentheses

Linear estimation after one-step weighting matrix is used. White cross-section standard errors and covariance with degree of freedom correction

Wald tests $H_{0}: \alpha=1$. It is distributed $\chi_{0.95,1}^{2}$

Japan's estimate is statistically equal to zero

countries, e.g., $\alpha_{\mathrm{i}}$, where $i=1 \ldots 7$, G7 countries. The average $\alpha$ estimate is 1.15 , which is statistically significantly different from zero. The Wald $P$ value indicates that we can reject the null hypothesis that the average $\alpha=1$; therefore, average $\alpha>1$

Thus, the implied average $\beta$ in this case is -0.15 . The fit is high. The estimates are White, cross-section standard errors and covariance with degrees of freedom corrections. We interpret $\alpha$ to mean that, on average, a 1\% increase in the level of human capital per researcher increases the growth rate of TFP (aggregate measure) per researcher by $1.15 \%$. Hence, a $1 \%$ increase in research effort increases TFP growth by more than $1 \%$ on average. The negative implied $\beta$ seems to be consistent with Bloom et al. (2020) interpretation that the increase in the number of researchers reduces TFP growth on average.

When $\alpha$ varies across countries, the estimated $\alpha_{\mathrm{i}}$ are significantly different from zero, except for Japan. The Wald $P$ values indicate that $\alpha$ is insignificantly different from one in Canada, the UK, and the USA only (i.e., $\alpha=1$ ); therefore, the implied $\beta \mathrm{s}$ are zero. For France and Italy, the $\alpha \mathrm{s}>1$; hence, the implied $\beta \mathrm{s}$ are -0.21 and -0.20 , respectively. Germany's $\alpha$ is 0.67 ; hence, $\beta$ is 0.33 .

We report the estimates of $\alpha$ using 2SLS in Tables 2 and 3. Table 2 reports the estimates using lagged values of the regressor in Eq. (3) as instruments. The estimated average $\alpha$ is 1.11, slightly smaller than the EGLS estimate above, and significantly different from zero. The Wald $P$ value of 0.2290 is high; thus, we cannot 
Table 2 2SLS estimates of pooled time-series-cross-section data. Sample (2000-2017) $\times 7 . \Delta \ln A_{\mathrm{it}}-\ln L_{\mathrm{it}}$ $=\alpha\left(\ln h_{\mathrm{it}}-\ln L_{\mathrm{it}}\right)+u_{\mathrm{it}}, u_{\mathrm{it}}=\eta_{\mathrm{i}}+v_{\mathrm{it}}$. The dependent variable is based on an aggregate measure TFP. The instruments are a constant and two lags of regressor

\begin{tabular}{lccllllll}
\hline & Estimate & $P$ value & Wald & $R^{2}$ & DW & $J P$ value & $\sigma$ & Implied $\beta$ \\
\hline $\boldsymbol{\alpha}$ & 1.11 & $(0.0000)$ & $(0.2290)$ & 0.98 & 2.11 & $(0.5727)$ & 0.11 & 0.00 \\
$\boldsymbol{\alpha}_{\mathbf{i}}$ & & & & & & & & \\
Canada & 0.60 & $(0.1306)$ & $(0.3268)$ & & & & 0.00 \\
France & 1.17 & $(0.0000)$ & $(0.0626)$ & & & & -0.17 \\
Germany & 0.74 & $(0.0000)$ & $(0.0282)$ & & & & 0.36 \\
Italy & 1.25 & $(0.0000)$ & $(0.0000)$ & & & & -0.25 \\
Japan & -0.25 & $(0.9344)$ & NA & & & & NA \\
UK & 0.89 & $(0.0000)$ & $(0.4440)$ & & & & 0.00 \\
USA & 0.56 & $(0.0000)$ & $(0.0002)$ & & & & 0.45 \\
$\bar{R}^{2}$ & 0.99 & & & & & \\
DW & 2.32 & & & & & \\
$\sigma$ & 0.11 & & & & & \\
$J P$ value & $(0.6050)$ & & & & & \\
\hline$A$
\end{tabular}

$A_{\mathrm{t}}$ is the aggregate TFP measure; $h_{\mathrm{t}}$ is the human capital; and $L_{\mathrm{t}}$ is the number of researchers

$P$ values are in parentheses

Estimation method is White cross-section standard errors and covariance with number of degrees of freedom correction

The Wald statistic tests $H_{0}: \alpha=1$. It is distributed $\chi_{0.95,1}^{2}$

The $J$ statistic tests the null hypothesis of instruments' over-identification restrictions

Japan's estimate is statistically equal to zero

reject the hypothesis that the average $\alpha$ is one, which is different from the EGLS estimate. Thus, the average implied $\beta$ is zero. The $J$ stat $P$ value is 0.5727 ; therefore, we cannot reject the instruments' over-identification restrictions. For $\alpha_{i}$, all the estimates are significantly different from zero, except for Japan. However, $\alpha$ for Canada and the UK, just like the EGLS estimates, is insignificantly different from one as the Wald $P$ values indicate. Thus, the implied $\beta$ s are zero. France's $\alpha$ is probably equal to one at the $10 \%$ level only. For Germany, Italy, and the USA, $\alpha$ is statistically different from one.

Table 3 reports the 2SLS estimates using a different set of instruments. We argued before that the population distribution, as an instrument, is consistent with the Life-Cycle Hypothesis. On average, the estimated $\alpha$ is 1.15 , which is identical to the EGLS estimate in Table 1 . The Wald $P$ value indicates that it is statistically different from one; therefore, $\beta$ is -0.15 on average. 
Table 32 2SLS estimates of pooled time-series-cross-section data. Sample (2000-2017) $\times 7 . \Delta \ln A_{\mathrm{it}}-\ln L_{\mathrm{it}}$ $=\alpha\left(\ln h_{\mathrm{it}}-\ln L_{\mathrm{it}}\right)+u_{\mathrm{it}}, u_{\mathrm{it}}=\eta_{\mathrm{i}}+v_{\mathrm{it}}$. The dependent variable is based on an aggregate measure TFP. The instruments include the logs of the age distribution, population age 15-19, 20-24, 25-29, 30-34, 35-39, $40-44,45-49,50-54,55-59$, and $60-64$ by country, and a constant

\begin{tabular}{lllllllll}
\hline & Estimate & $P$ value & Wald & $R^{2}$ & DW & $J P$ value & $\sigma$ & Implied $\beta$ \\
\hline $\boldsymbol{\alpha}$ & 1.15 & $(0.0000)$ & $(0.0003)$ & 0.99 & 2.11 & $(0.1476)$ & 0.11 & -0.14 \\
$\boldsymbol{\alpha}_{\mathbf{i}}$ & & & & & & & & \\
Canada & 0.95 & $(0.0020)$ & $(0.8809)$ & & & & 0.00 \\
France & 1.20 & $(0.0000)$ & $(0.0068)$ & & & & -0.20 \\
Germany & 0.66 & $(0.0000)$ & $(0.0031)$ & & & & 0.43 \\
Italy & 1.20 & $(0.0000)$ & $(0.0000)$ & & & & -0.20 \\
Japan & 0.07 & $(0.9441)$ & NA & & & & NA \\
UK & 1.35 & $(0.0000)$ & $(0.2537)$ & & & & 0.00 \\
USA & 0.83 & $(0.0000)$ & $(0.4020)$ & & & & 0.00 \\
$\bar{R}^{2}$ & 0.98 & & & & & & \\
DW & 2.56 & & & & & & \\
$\sigma$ & 0.11 & & & & & & \\
$J P$ value & $(0.8585)$ & & & & & \\
\hline
\end{tabular}

$A_{\mathrm{t}}$ is the aggregate TFP measure; $h_{\mathrm{t}}$ is the human capital; and $L_{\mathrm{t}}$ is the number of researchers

$P$ values are in parentheses

Estimation method is White cross-section standard errors and covariance with number of degrees of freedom correction

The Wald statistic tests $H_{0}: \alpha=1$. It is distributed $\chi_{0.95,1}^{2}$

The $J$ statistic tests the null hypothesis of instruments' over-identification restrictions

Japan's estimate is statistically equal to zero

For $\alpha_{i}$, all estimates are significantly different from zero, except for Japan. However, the Wald $P$ values indicate that only Canada, the UK, and the USA are statistically significantly indifferent from one, i.e., $\alpha=1$. France, Germany, and Italy have estimates of $\alpha>1$. These results are almost identical to those of EGLS reported in Table 1. The fit is high. The estimated standard errors are White cross-section and degrees of freedom corrected. The $J P$ value indicates that we cannot reject the instruments' over-identification restrictions.

Tables 4 and 5 report the GMM estimates. Table 4 reports the GMM estimates when the instruments are just the lags of the regressor and a constant term. In the first row, the average $\alpha$ is 1.03 , statistically significant, and statistically insignificant from one as indicated by the Wald $P$ value. This is similar to the 2SLS estimate, where the same instruments were used. The $J$ statistic $P$ value indicates 
Table 4 GMM estimates of pooled time-series-cross-section data. Sample $(2000-2017) \times 7 . \Delta \ln A_{\mathrm{it}}$ $-\ln L_{\mathrm{it}}=\alpha\left(\ln h_{\mathrm{it}}-\ln L_{\mathrm{it}}\right)+u_{\mathrm{it}}, u_{\mathrm{it}}=\eta_{\mathrm{i}}+v_{\mathrm{it}}$. The dependent variable is based on an aggregate measure TFP. The instruments include a constant and two lags of the regressor

\begin{tabular}{lclllllll}
\hline & Estimate & $P$ value & Wald & $R^{2}$ & DW & $J P$ value & $\sigma$ & Implied $\beta$ \\
\hline $\boldsymbol{\alpha}$ & 1.03 & $(0.0000)$ & $(0.5078)$ & 0.98 & 2.43 & $(0.8654)$ & 0.11 & -0.03 \\
$\boldsymbol{\alpha}_{\mathbf{i}}$ & & & & & & & & \\
Canada & 0.60 & $(0.1306)$ & $(0.3268)$ & & & & 0.00 \\
France & 1.17 & $(0.0000)$ & $(0.0626)$ & & & & -0.17 \\
Germany & 0.74 & $(0.0000)$ & $(0.0282)$ & & & & 0.26 \\
Italy & 1.25 & $(0.0000)$ & $(0.0000)$ & & & & -0.25 \\
Japan & -0.25 & $(0.9344)$ & NA & & & & NA \\
UK & 0.89 & $(0.0000)$ & $(0.4440)$ & & & & 0.00 \\
USA & 0.56 & $(0.0000)$ & $(0.0002)$ & & & & 0.44 \\
$\bar{R}^{2}$ & 0.99 & & & & & \\
DW & 2.32 & & & & & \\
$\sigma$ & 0.11 & & & & & \\
$J P$ value & $(0.6050)$ & & & & & \\
\hline
\end{tabular}

$A_{\mathrm{t}}$ is the aggregate TFP measure; $h_{\mathrm{t}}$ is the human capital; and $L_{\mathrm{t}}$ is the number of researchers

$P$ values are in parentheses

2SLS instrument weighting matrix. Estimation is linear after one-step weighting matrix and White crosssection standard errors and covariance with degrees of freedom corrections

The Wald statistic tests $H_{0}: \alpha=1$. It is distributed $\chi_{0.95,1}^{2}$

The $J$ statistic tests the null hypothesis of instruments' over-identification restrictions

Japan's estimate is statistically equal to zero

that we cannot reject the instrument's over-identification restrictions. For $\alpha_{i}$, the parameter estimates are identical to those from 2SLS reported earlier. They are also statistically equivalent.

Table 5 reports the GMM estimates using the second set of instruments, the population distribution. On average, $\alpha$ is different from the 2SLS estimate; the GMM estimate is 1.05, significant; however, the Wald $P$ value indicates that the GMM estimate is insignificantly different from one while the 2SLS was different from one. Overall, the average estimates of $\alpha$ using different estimators and different instruments are close in magnitude and the country estimates of $\alpha$ are identical in 2SLS and GMM when the instruments are the same. All estimates of $\alpha$ are significant, and in a few cases were not different from one. The regressions then reflect the scatter plot in Fig. 4 remarkably well. 
Table 5 GMM estimates of pooled time-series-cross-section data. Sample $(2000-2017) \times 7 . \Delta \ln A_{\text {it }}$ $-\ln L_{\mathrm{it}}=\alpha\left(\ln h_{\mathrm{it}}-\ln L_{\mathrm{it}}\right)+u_{\mathrm{it}}, u_{\mathrm{it}}=\eta_{\mathrm{i}}+v_{\mathrm{it}}$. The dependent variable is based on an aggregate measure TFP. The instruments include the logs of the age distribution, population age 15-19, 20-24, 25-29, $30-34,35-39,40-44,45-49,50-54,55-59$, and $60-64$ by country, and a constant

\begin{tabular}{lllllllll}
\hline & Estimate & $P$ value & Wald & $R^{2}$ & DW & $J P$ value & $\sigma$ & Implied $\beta$ \\
\hline $\boldsymbol{\alpha}$ & 1.04 & $(0.0000)$ & $(0.4959)$ & 0.98 & 2.41 & $(1.0000)$ & 0.11 & 0.00 \\
$\boldsymbol{\alpha}_{\mathbf{i}}$ & & & & & & & \\
Canada & 0.95 & $(0.0012)$ & $(0.8755)$ & & & & 0.00 \\
France & 1.21 & $(0.0000)$ & $(0.0041)$ & & & & -0.21 \\
Germany & 0.66 & $(0.0000)$ & $(0.0016)$ & & & & 0.34 \\
Italy & 1.20 & $(0.0000)$ & $(0.0000)$ & & & & -0.20 \\
Japan & NA & NA & NA & & & & NA \\
UK & 1.35 & $(0.0000)$ & $(0.2284)$ & & & & 0.00 \\
USA & 0.83 & $(0.0000)$ & $(0.3812)$ & & & & 0.00 \\
$\bar{R}^{2}$ & 0.99 & & & & & \\
DW & 2.28 & & & & & \\
$\sigma$ & 0.11 & & & & & \\
$J P$ value & $(0.4201)$ & & & & & \\
\hline
\end{tabular}

$A_{\mathrm{t}}$ is the aggregate TFP measure; $h_{\mathrm{t}}$ is the human capital; and $L_{\mathrm{t}}$ is the number of researchers

$P$ values are in parentheses

2SLS instrument weighting matrix. Estimation is linear after one-step weighting matrix and White crosssection standard errors and covariance with degrees of freedom corrections

The Wald statistic tests $H_{0}: \alpha=1$. It is distributed $\chi_{0.95,1}^{2}$

The $J$ statistic tests the null hypothesis of instruments' over-identification restrictions

Japan's estimate is statistically equal to zero

Finally, we estimate the same equation using the same estimators but with a different measure of TFP, which we believe is more consistent with growth theory because it measures market productivity more closely. Aggregate TFP data may not be an appropriate measure of productivity since the aggregates include government and service industries whose productivity levels are imprecisely measured because outputs are hard to measure in these sectors. For this reason, we re-estimate the model using a market economy measure of TFP. The EUKLEMS data set includes data for TFP excluding a number of sectors of the total economy (Stehrer et al., 2019). The data set excludes Canada (see the data Appendix). 
Market Economy Measure of TFP Growth and Human Capital Level per Researcher

France

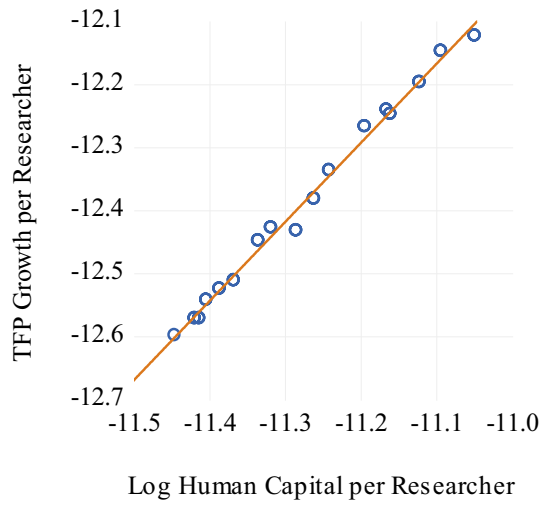

Italy

$-11.0$

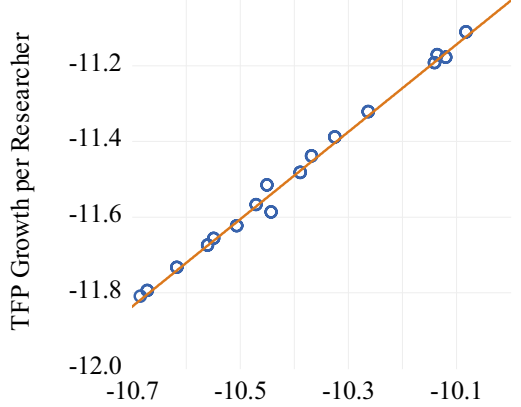

Log Human Capital per Researcher

U.K.

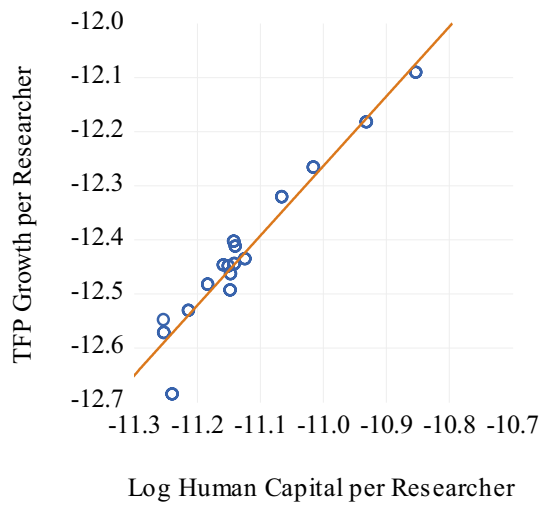

Germany

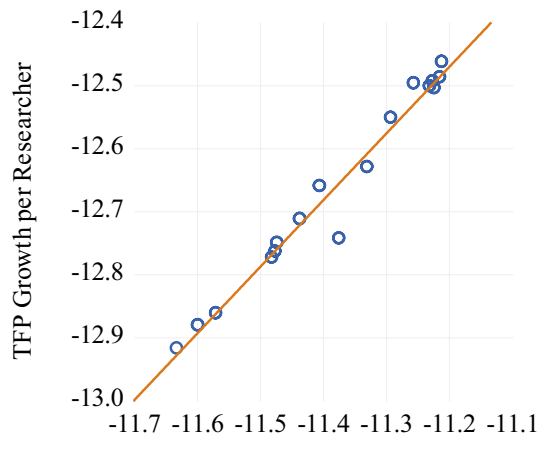

Log Human Capital per Researcher

Japan

$-13.30$

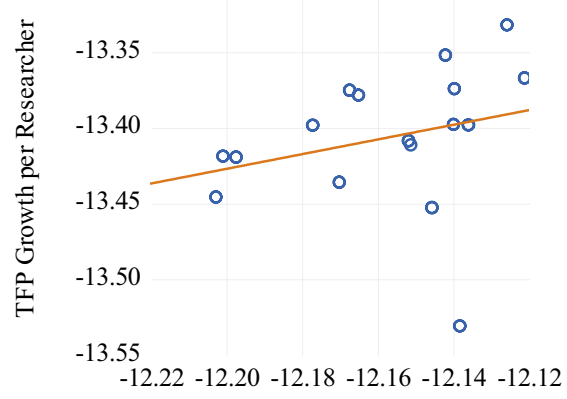

Log Human Capital per Researcher

U.S.

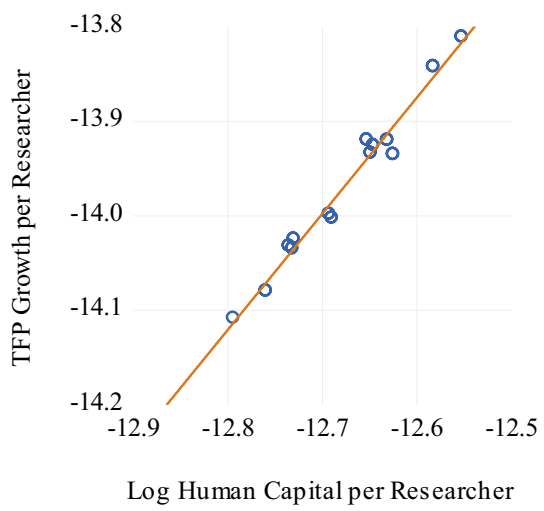

Fig. 5 Market economy measure of TFP growth and human capital level per researcher 
Table 6 EGLS estimates of the G6 pooled time-series-cross-section data. Sample (2000-2017) $\times 6 . \Delta$ $\ln A_{\mathrm{it}}-\ln L_{\mathrm{it}}=\alpha\left(\ln h_{\mathrm{it}}-\ln L_{\mathrm{it}}\right)+u_{\mathrm{it}}, u_{\mathrm{it}}=\eta_{\mathrm{i}}+v_{\mathrm{it}}$. The dependent variable is based on a market measure of TFP

\begin{tabular}{llllllll}
\hline & Estimate & $P$ value & Wald & $R^{2}$ & DW & $\sigma$ & Implied $\beta$ \\
\hline $\boldsymbol{\alpha}$ & 1.17 & $(0.0000)$ & $(0.0000)$ & 0.99 & 1.74 & 0.03 & -0.17 \\
$\boldsymbol{\alpha}_{\mathbf{i}}$ & & & & & & & \\
Canada & NA & NA & NA & & & & NA \\
France & 1.25 & $(0.0000)$ & $(0.0000)$ & & & & -0.25 \\
Germany & 1.05 & $(0.0000)$ & $(0.0048)$ & & & & -0.05 \\
Italy & 1.15 & $(0.0000)$ & $(0.0000)$ & & & & -0.15 \\
Japan & 0.48 & $(0.1577)$ & NA & & & & NA \\
UK & 1.28 & $(0.0000)$ & $(0.0004)$ & & & & -0.28 \\
USA & 1.23 & $(0.0000)$ & $(0.0000)$ & & & & -0.23 \\
$\bar{R}^{2}$ & 0.99 & & & & & \\
DW & 2.15 & & & & & \\
$\sigma$ & 0.03 & & & & & \\
\hline
\end{tabular}

$A_{\mathrm{t}}$ is the TFP market measure; $h_{\mathrm{t}}$ is the human capital; and $L_{\mathrm{t}}$ is the number of researchers

$P$ values are in parentheses

Linear estimation after one-step weighting matrix, White cross-section standard errors and covariance matrix with a degree of freedom correction

The Wald statistic tests $H_{0}: \alpha=1$. It is distributed $\chi_{0.95,1}^{2}$

Japan is insignificant

EUKLEMS does not report market TFP for Canada

The US sample is 2000-2014

\section{Estimation Using a Market TFP Measure}

Figure 5 is a scatter plot of TFP growth rate per researcher, market measure, and human capital per researcher. The fit is much better than Fig. 4, and it improved greatly for Japan. ${ }^{5}$ We use EGLS, 2SLS, and GMM to estimate the fixed-effect model with the G7 countries pooled time-series-cross-section data from 2000 to 2017. The results are reported in Tables 6, 7, 8, 9, and 10. In general, we obtain very similar results across estimators. For average $\alpha$, the IV estimators give identical results: $1.11,1.15,1.03$, and 1.05 for 2SLS with lag instruments, 2 SLS with population distribution instruments, GMM with lag instruments, and GMM with population distribution instruments respectively. The EGLS estimates are insignificantly different: 1.17 and 1.15 respectively. Hence, we interpret these elasticities the same way. On average across the G6 (G7 less Canada), a 1\% increase in research effort increases TFP growth by 1 or slightly more than $1 \%$.

\footnotetext{
${ }^{5}$ We use a chi-squared $95 \%$ confidence ellipse to test the correlation.
} 


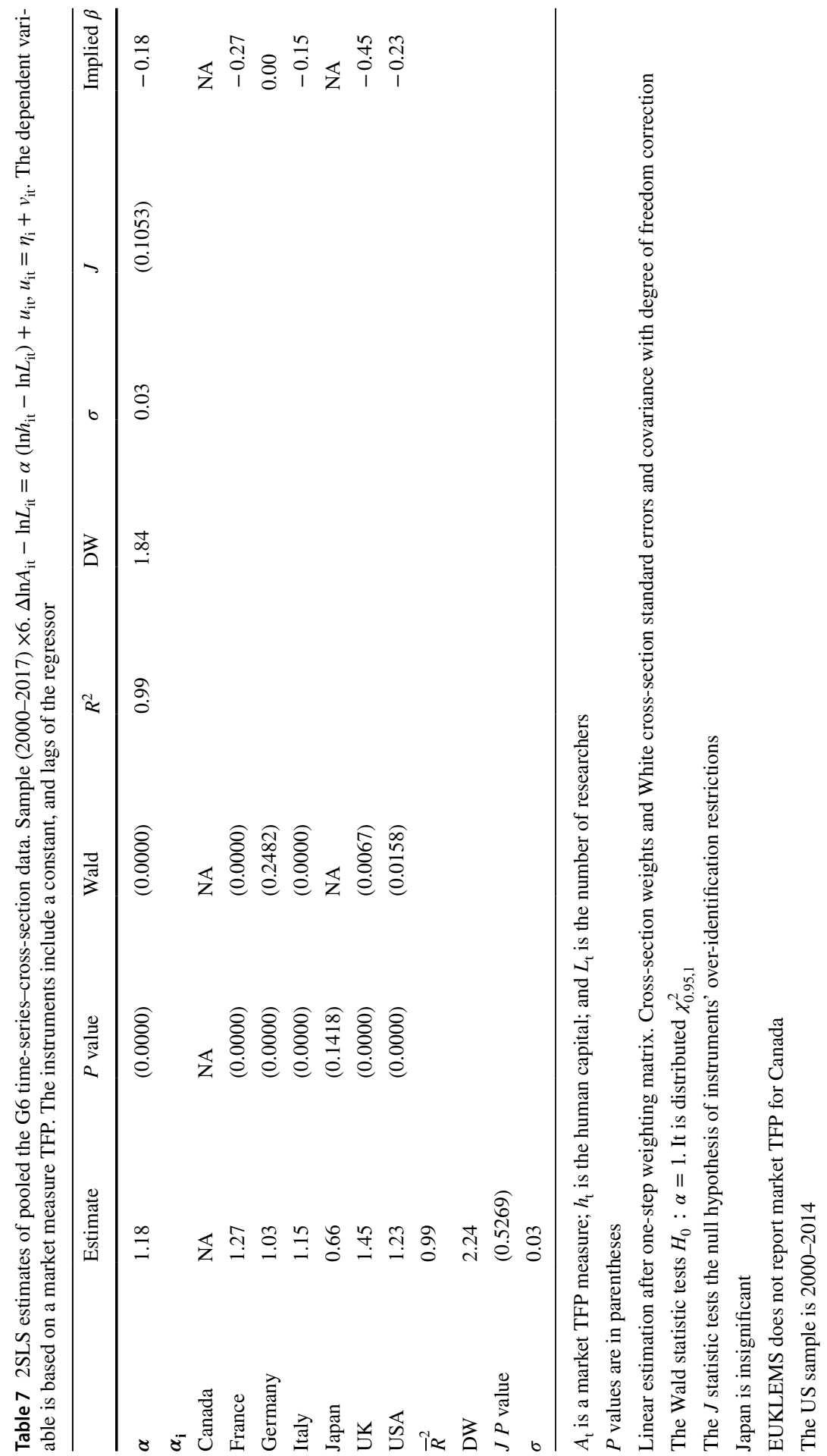




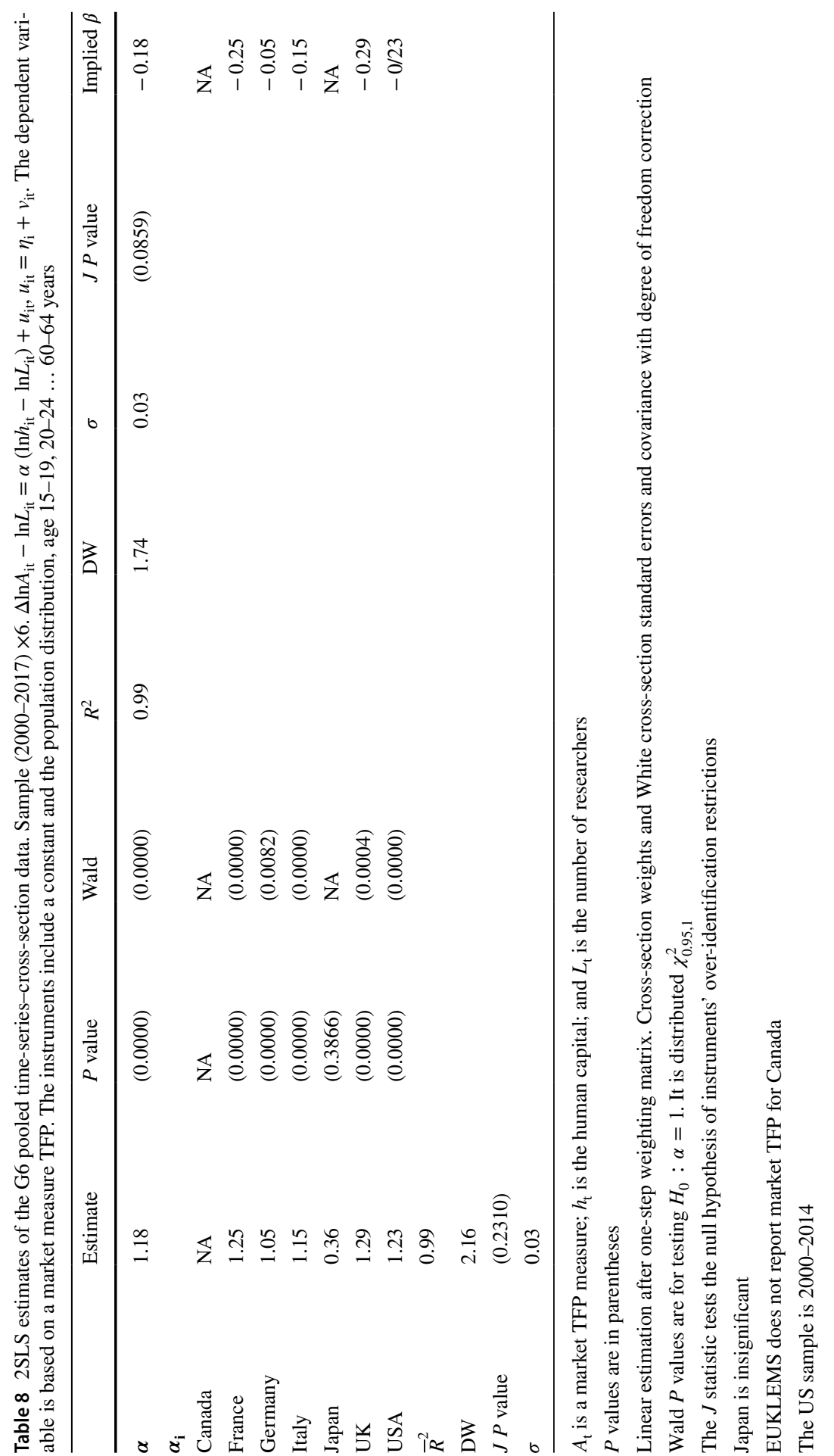




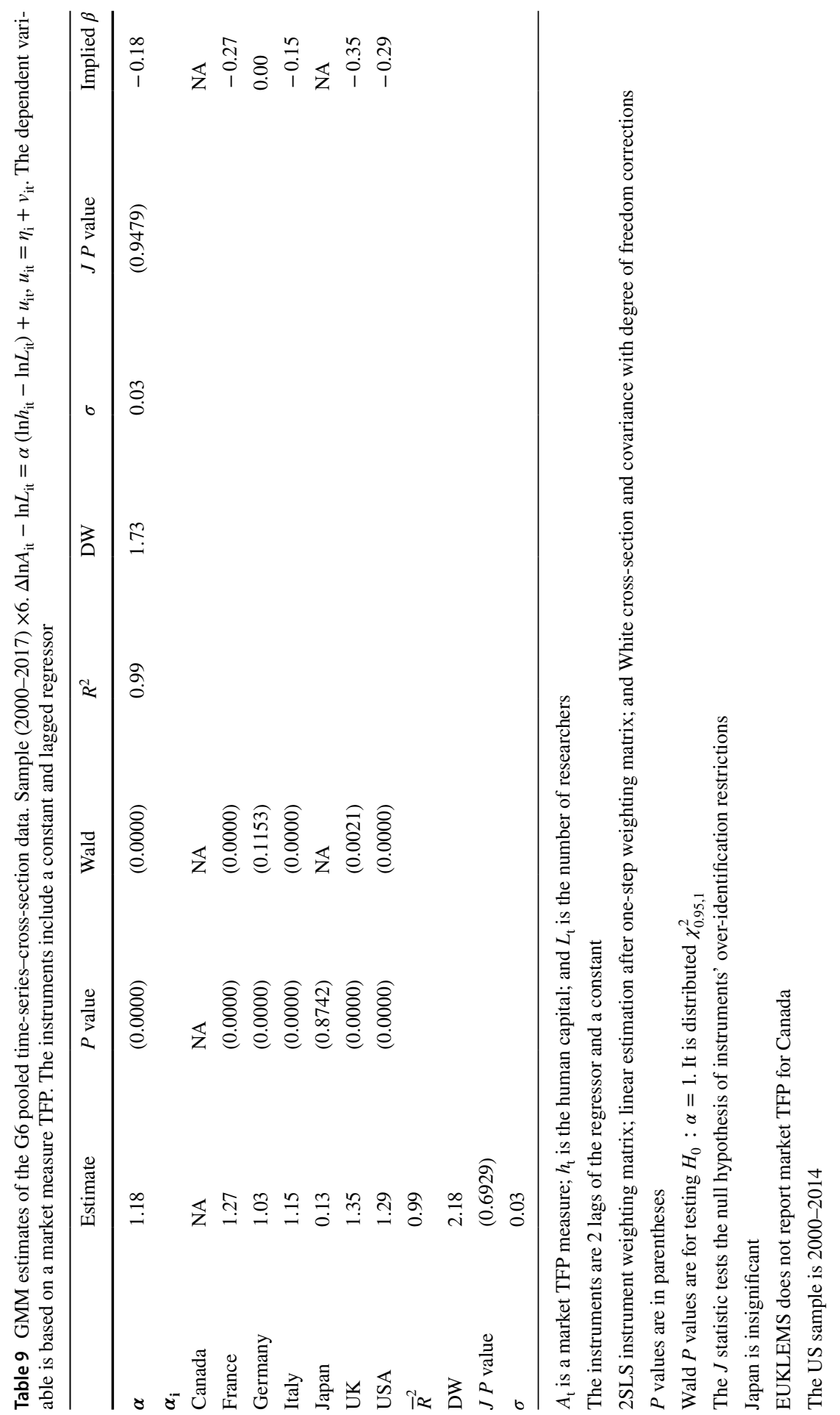




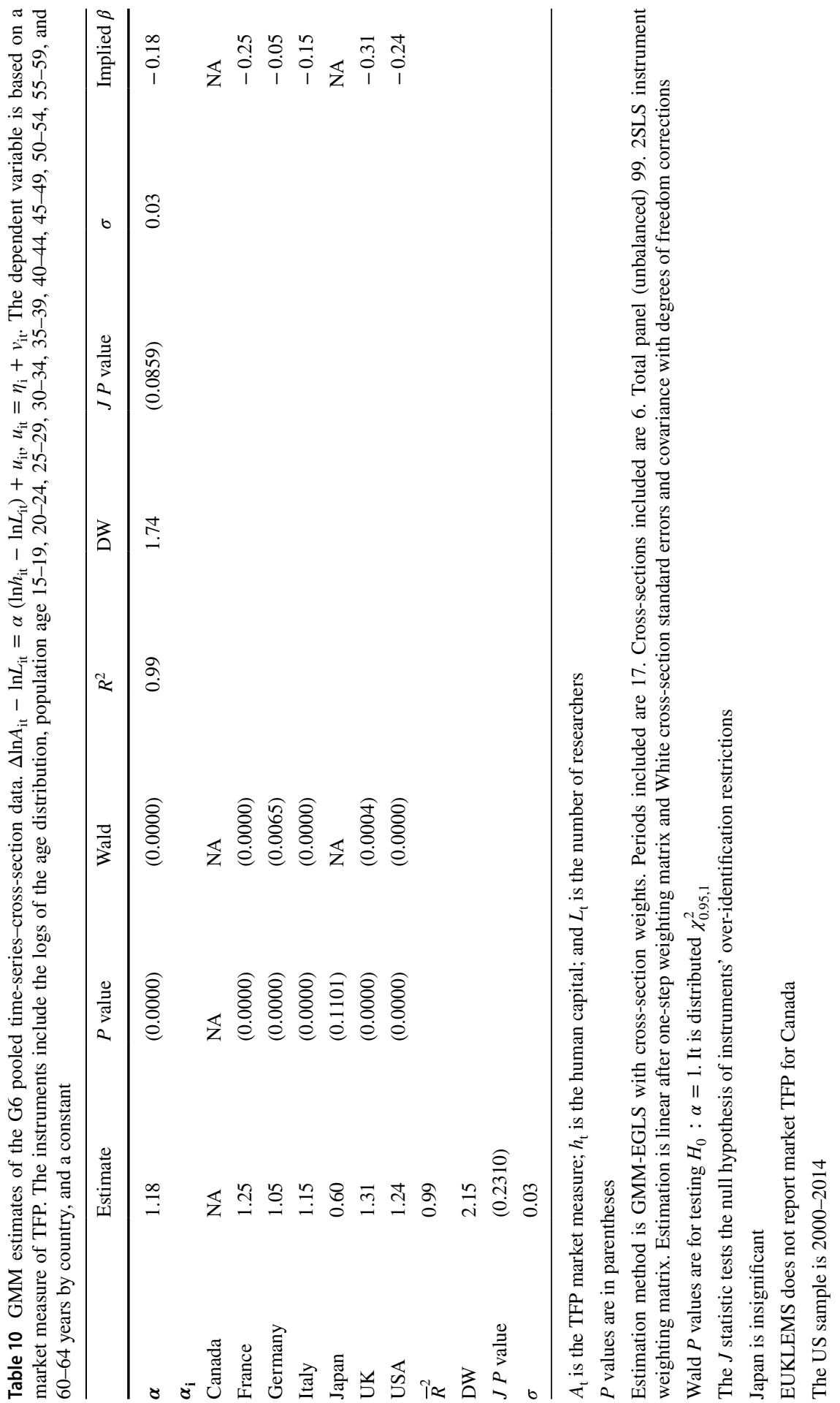




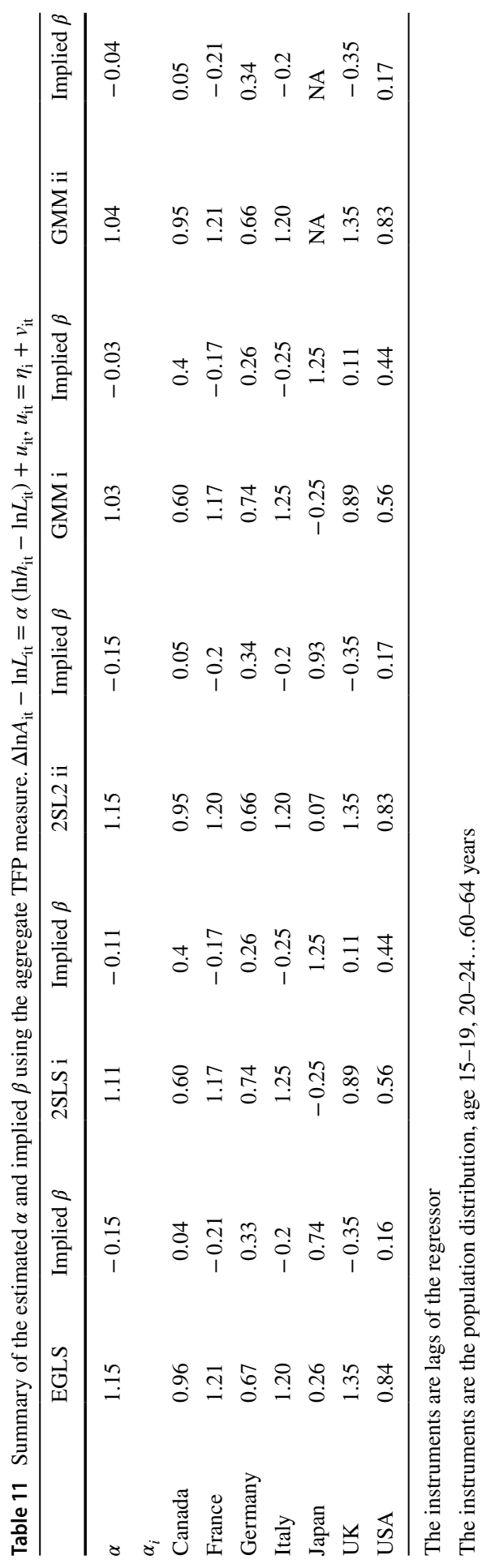


Table 12 Summary of the estimated $\alpha$ and implied $\beta$ using the market TFP. $\Delta \ln A_{\mathrm{it}}-\ln L_{\mathrm{it}}=\alpha\left(\ln h_{\mathrm{it}}\right.$ $\left.-\ln L_{\mathrm{it}}\right)+u_{\mathrm{it}}, u_{\mathrm{it}}=\eta_{\mathrm{i}}+v_{\mathrm{it}}$

\begin{tabular}{lllllllllll}
\hline$\alpha$ & EGLS & Implied & 2SLS i & Implied & 2SLSii & Implied & GMM i & Implied & GMM ii & Implied \\
\hline$\alpha_{\mathrm{i}}$ & 1.17 & -0.17 & 1.18 & -0.18 & 1.18 & -0.18 & 1.18 & -0.18 & 1.18 & -0.18 \\
Canada & NA & NA & NA & NA & NA & NA & NA & NA & NA & NA \\
France & 1.25 & -0.25 & 1.27 & -0.27 & 1.25 & -0.25 & 1.27 & -0.27 & 1.25 & -0.25 \\
Germany & 1.05 & -0.05 & 1.03 & -0.03 & 1.05 & -0.05 & 1.03 & -0.03 & 1.05 & -0.05 \\
Italy & 1.15 & -0.15 & 1.15 & -0.15 & 1.15 & -0.15 & 1.15 & -0.15 & 1.15 & -0.15 \\
Japan & 0.48 & NA & 0.66 & NA & 0.36 & NA & 0.13 & NA & 0.60 & NA \\
U.K & 1.28 & -0.28 & 1.45 & -0.45 & 1.29 & -0.29 & 1.35 & -0.35 & 1.31 & -0.31 \\
U.S & 1.23 & -0.23 & 1.23 & -0.23 & 1.23 & -0.23 & 1.29 & -0.29 & 1.24 & -0.24 \\
\hline
\end{tabular}

The instruments are lags of the regressor

The instruments are the population distribution, age 15-19, 20-24...60-64 years

For $\alpha_{\mathrm{i}}$, just like the previous set of results of the aggregate TFP measure, the parameter estimates of 2SLS and GMM are identical when the instruments are the same. All estimated parameters are statistically significantly different from zero, except Japan although the magnitude of $\alpha$ is now larger in magnitude than before. The diagnostic statistics are similar too. The interpretation remains unchanged. The increase in research effort by $1 \%$ increases TFP growth by more than $1 \%$, and the increase in the number of researchers has been associated with declining TFP growth.

Tables 11 and 12 are summaries of the parameter estimates. The overall results indicate that (1) the increase in research effort increases TFP growth. The elasticity is between 1 and slightly greater than 1 . The estimates are robust to estimators and the fit of the equation is high, which supports the theory and the specification of the model. (2) The implied responsiveness of TFP growth to the number of researchers is negative to zero. This result is consistent with the findings of Bloom et al. (2020), which may indicate that the increase in the number of researchers has not generated useful knowledge. (3) The market measure of TFP fits the model better than the aggregate measure because it measures output more precisely by excluding the services and government sectors. (4) Japan is the only country in the G7 whose TFP growth is different. The model does not fit the Japanese data and the parameter estimate is insignificantly different from zero. (5) The differences in the magnitudes of the responsiveness of TFP growth to research effort across the G7 vary between Canada, the UK, and the USA on one side and the European countries on the other. The Anglophone countries' $\alpha$ is $\approx 1$ (implied $\beta=0$ ) while the European countries' $\alpha>1$ (implied $\beta<0$ ). In summary, the macro-evidence supports the micro-theory strongly for the G7 data. 


\section{Conclusion}

We examine the prediction of the micro-founded endogenous growth theory that TFP growth is proportional to the level of effective research effort. We estimate a two-equation representation of this key relationship, whereby the effective research effort is assumed to be a nonlinear product of the stock of human capital and the number of researchers engaged in $R \& D$ in the $G 7$ countries. We use annual data from 2000 to 2017 for the G7 countries. To remedy the small sample and the endogeneity biases, we use a number of estimators, e.g., EGLS and two IV estimators, namely 2SLS and GMM, to estimate a fixed-effect model with a panel of pooled time-series-cross-section.

We show that there is a significant relationship between the level of research effort and aggregate TFP growth. On average (i.e., across the G7 from 2000 to 2017), the estimated elasticity of research effort with respect to TFP growth is either statistically indifferent from one or slightly higher than one; however, it varies across the G7. Japan is the only country in the G7 where research effort does not have a significant effect on TFP growth. There is also a noticeable difference in the magnitude of the parameter estimates in Canada, the UK, and the USA (the Anglophone countries) on one hand, and the European countries France, Germany, and Italy on the other. The formers' estimates are insignificantly different from one, while the European countries' estimates are greater than one. The European countries' data fit is better too. However, on average, for the G7, a $1 \%$ increase in research effort increases TFP growth per researcher by $1.096 \%$.

In addition to the aggregate TFP measure, we tested the same relationship using a market measure of TFP, which excludes public sectors and service sectors, where the measurement of output is imprecise, and showed that the relationship between TFP growth and research effort is even stronger. Interestingly, the results also indicate that the increase in research effort increases TFP growth and the fit of the model improves for all countries including Japan. It suggests that the relationship between research effort and the market economy measure of TFP growth fits the model best. Note that the scatter plots of the data show that too before estimation. The average elasticity is $1.18 \%$. If we take all the parameter estimates across the G7 countries using aggregate and market TFP, the average estimate of the elasticity of research effort with respect to TFP growth is $1.14 \%$.

The empirical evidence provided in this paper is supportive of the theory of endogenous growth process, which essentially attributes economic growth to research effort. Knowledge is hard to measure. Economists used a variety of measures to proxy knowledge as we described earlier. In this paper, it is research effort that drives TFP growth. We assumed that is a nonlinear function of the product of the level of human capital and the number of people engaged in R\&D. The firm chooses these levels endogenously. There might be a significant role for government policy to play in building the stock of human capital and in incentivizing research, e.g., pursuing evidence-based policies and investing in education and research capacity.

Future empirical research in this area should address a number of underresearched issues. First, typically, human capital is measured by average years of 
schooling. ${ }^{6}$ However, there is a heterogeneity problem. For example, 1 year of schooling in a developed country has a different outcome than 1 year of schooling in a developing country. The educational outcomes also vary across developed countries, and within every developed country from one institute to another. Therefore, future research should account for the heterogeneity of quality of human capital. However, the adjustment is daunting (see Razzak et al. (2016, p.173) for example).

Second, the literature on the production of knowledge has expanded in different directions. For example, Gibbons et al. (1994) introduced the idea of modes of production of knowledge. Mode 1 refers to the typical university academic research and Mode 2 focuses on the research application. Etzkowitz and Leydesdorff (1995, 2000) introduced the Triple Helix Model of Innovation as a set of interactions between academia, industry, and government to advance economic and social development, as described in concepts such as the knowledge economy. Carayannis and Campbell (2012), and in a number of papers on the production modes, e.g., Carayannis and Campbell (2006, 2011), argued that the quality assurance of R\&D should also involve the end users in addition to peer review of academic research, and should give more weight to the outcome and usefulness of this research. Future research should test the predictions of these models. ${ }^{7}$

In addition, future research should attempt to examine the effect of this endogenous TFP model on real GDP per capita and most importantly on the real GDP per capita differentials. The question is whether cross-country differences in research efforts explain income per capita differentials, and how much they explain beyond what factor inputs, i.e., capital and labor do.

\section{Appendix}

The sample is 2000 to 2017. Human capital: source Penn World Table 9.1. The data of the number of researchers are from the World Bank data set. Researchers are professionals who conduct research and improve or develop concepts, theories, models, techniques instrumentation, and software of operational methods. R\&D covers basic research, applied research, and experimental development. We use total population data to obtain the number of researchers.

Total population data are from the Penn World Table 9.1 to convert researchers per million people into an absolute number of researchers. TFP growth rate is from the Conference Board. TFP market measure is taken from EUKLEMS (2000-2017)

\footnotetext{
6 Typically, human capital is measured by average years of schooling and returns on education. Human capital level $h_{t}$ is $e^{\psi l_{h t}}$, where $\psi>0$. This equation is consistent with Mincer (1974), and Bils and Klenow (2000) in the sense that human capital data are based on average years of schooling and the rate of return on education $\psi$.

7 One way to do that is to define and measure research effort in Eq. (2) as the intersections of university research with the industry research and with government research, which requires data on the number of researchers and their levels of human capital adjusted for quality in each of these sectors. Then test the hypotheses that $\$ \$ \backslash$ alpha $=0 \$ \$$ and $\$ \$ \backslash$ alpha $=1 \$ \$$ in Eq. (3). There are two apparent issues: the availability of the data and quality adjustment.
} 
except for the USA, where the sample is 2000-2014 for the market economy TFP measure. The Market Economy measure excludes lines L, O, P, Q, T, and U from the data set, which are the sectors' real estate activity; public administration and defense; compulsory social security; education, health, and social work; and activities of households as employers; undifferentiated goods- and services-producing activities of households for own use.

The population distribution is from the World Bank Development Indicators.

Acknowledgements I thank John Seater for his insights, constructive comments, and rigorous discussion. I also thank two anonymous referees for their comments.

Funding Open Access funding enabled and organized by CAUL and its Member Institutions.

Open Access This article is licensed under a Creative Commons Attribution 4.0 International License, which permits use, sharing, adaptation, distribution and reproduction in any medium or format, as long as you give appropriate credit to the original author(s) and the source, provide a link to the Creative Commons licence, and indicate if changes were made. The images or other third party material in this article are included in the article's Creative Commons licence, unless indicated otherwise in a credit line to the material. If material is not included in the article's Creative Commons licence and your intended use is not permitted by statutory regulation or exceeds the permitted use, you will need to obtain permission directly from the copyright holder. To view a copy of this licence, visit http://creativecommons.org/ licenses/by/4.0/.

\section{References}

Aghion, P., \& Howitt, P. (1992). A model for growth through creative destruction. Econometrica, 60(2), 323-351.

Akcigit, U., \& Liu, Q. (2016). The role of information in innovation and competition. Journal of the European Economic Association, 14(4), 828-870.

Bils, M., \& Klenow, P. J. (2000). Does schooling cause growth? American Economic Review, 90(5), 1160-83.

Bloom, N. C., Jones, C., van Reenen, J., \& Webb, M. (2020). Are ideas getting harder to find? American Economic Review, 110(4), 1104-1144.

Carayannis, E. G., \& Campbell, D. F. J. (2006). Mode 3: Meaning and implications from a knowledge systems perspective. In Knowledge creation, diffusion, and use in innovation networks and knowledge clusters: A comparative systems approach across the United States, Europe, and Asia (pp. 1-25). Praeger Publishers.

Carayannis, E. G., \& Campbell, D. F. J. (2011). Open innovation diplomacy and a 21st century Fractal Research, Education and Innovation (FREIE) ecosystem: Building on the quadruple and quintuple helix innovation concepts and the "mode 3" knowledge production system. Journal of the Knowledge Economy, 2(3), 327-372.

Carayannis, E. G., \& Campbell, D. F. J. (2012). Mode 3 knowledge production in quadruple helix innovation systems: 21st century democracy, innovation, and entrepreneurship for development. Springer Briefs in Business 7. New York, NY: Springer.

Coffey, B., McLaughlin, P. A., \& Peretto, P. (2020). The cumulative cost of regulations. Review of Economic Dynamics, 38, 1-21.

Dawson, J. W., \& Seater, J. (2013). Federal regulation and aggregate economic growth. Journal of Economic Growth, 18, 137-177.

Etzkowitz, H., \& Leydesdorff, L. (1995). The Triple Helix - university-industry-government relations: A laboratory for knowledge based economic development. EASST Review, 14, 14-19.

Etzkowitz, H., \& Leydesdorff, L. (2000). The dynamics of innovation: From national systems and mode 2 to a Triple Helix of university-industry-government relations. Research Policy, 29(2), 109-123. 
Gibbons, M., Limoges, C., Nowotny, H., Schwartzman, S., Scott, P., \& Trow, M. (1994). The new production of knowledge: The dynamics of science and research in contemporary societies. Sage.

Jones, C. I. (2002). Sources of U.S. economic growth in a world of ideas. American Economic Review, 92(1), 220-239

Jones, C. I., \& Kim, J. (2018). A Schumpeterian model of top income inequality. Journal of Political Economy, 126(5), 1785-1826.

Kuznets, S. (1973). Modern economic growth: Findings and reflections. American Economic Review, 63(3), 247-258.

Lucas, R., Jr. (1988). On the mechanics of economic development. Journal of Monetary Economics, 22(1), 3-42. https://doi.org/10.1016/0304-3932(88)90168-7

Lucas, R., Jr. (2009). Ideas and growth. Economica, 76(301), 1-19. https://doi.org/10.1111/j.1468-0335. 2008.00748.x

Mincer, J. (1974). Schooling, experience, and earnings. Columbia University Press.

Nelson, R., \& Phelps, E. (1966). Investments in humans, technological diffusion, and economic growth. American Economic Review, Papers and Proceedings, 56(1/2), 69-75.

Phelps, E. S. (1966). Models of technical progress and the golden rule of research. Review of Economic Studies, 33(2), 133-145.

Razzak, W. A., Laabas, B., \& Bentour, E. M. (2016). The dynamics of technical progress in some developing and developed countries. In M. M. Erdoğdu, \& B. Christiansen (Eds.), The Handbook of Research on Comparative Economic Development Perspectives on Europe and the MENA Region (chapter 9, pp. 172-194). IGI Global Research Publishing, USA.

Romer, P. (1990a). Endogenous technological change. Journal of Political Economy, 98 (5, Part 2), S71-S102.

Romer, P. (1990b). Human capital and growth: Theory and evidence. Carnegie-Rochester Conference Series on Public Policy, 32, 251-286. https://doi.org/10.1016/0167-2231(90)90028-J

Stehrer, R., Bykova, A., Jäger, K., Reiter, O., \& Schwarzhappel, M. (2019). Industry level growth and productivity data with special focus on intangible assets report on methodologies and data construction for the EU KLEMS Release 2019.

Wooldridge, J. M. (2001). Econometric analysis of cross section and panel data. MIT, ISBN 13-978-0262-23219-7 and 0-262-23219-7.

Publisher's Note Springer Nature remains neutral with regard to jurisdictional claims in published maps and institutional affiliations. 